\title{
BMJ Open Role of social deprivation on asthma care quality among a cohort of children in US community health centres
}

\author{
Jennifer A Lucas (D) , ${ }^{1}$ Miguel Marino, ${ }^{1,2}$ Katie Fankhauser, ${ }^{1}$ Andrew Bazemore, ${ }^{3}$ \\ Sophia Giebultowicz, ${ }^{4}$ Stuart Cowburn, ${ }^{4}$ Jorge Kaufmann, ${ }^{1}$ David Ezekiel-Herrera, ${ }^{1}$ \\ John Heintzman ${ }^{1,4}$
}

To cite: Lucas JA, Marino M, Fankhauser $\mathrm{K}$, et al. Role of social deprivation on asthma care quality among a cohort of children in US community health centres. BMJ Open 2021;11:e045131. doi:10.1136/ bmjopen-2020-045131

- Prepublication history and additional supplemental material for this paper are available online. To view these files, please visit the journal online. To view these files, please visit the journal online (http://dx.doi org/10.1136/bmjopen-2020045131).

Received 24 September 2020 Accepted 09 June 2021

Check for updates

(C) Author(s) (or their employer(s)) 2021. Re-use permitted under CC BY-NC. No commercial re-use. See rights and permissions. Published by BMJ.

${ }^{1}$ Family Medicine, Oregon Health \& Science University, Portland,

Oregon, USA

${ }^{2}$ School of Public Health, Oregon Health \& Science University,

Portland, Oregon, USA

${ }^{3}$ American Board of Family

Medicine, Lexington, Kentucky, USA

${ }^{4}$ OCHIN, Portland, Oregon, USA

Correspondence to

Dr Jennifer A Lucas;

lucasje@ohsu.edu

\section{ABSTRACT}

Objective Social deprivation is associated with worse asthma outcomes. The Social Deprivation Index is a composite measure of social determinants of health used to identify neighbourhood-level disadvantage in healthcare. Our objective was to determine if higher neighbourhoodlevel social deprivation is associated with documented asthma care quality measures among children treated at community health centres (CHCs).

Methods (setting, participants, outcome measures) We used data from CHCs in 15 states in the Accelerating Data Value Across a National Community Health Center Network (ADVANCE). The sample included 34266 children with asthma from 2008 to 2017, aged 3-17 living in neighbourhoods with differing levels of social deprivation measured using quartiles of the Social Deprivation Index score. We conducted logistic regression to examine the odds of problem list documentation of asthma and asthma severity, and negative binomial regression for rates of albuterol, inhaled steroid and oral steroid prescription adjusted for patient-level covariates.

Results Children from the most deprived neighbourhoods had increased rates of albuterol (rate ratio $(R R)=1.22,95 \%$ $\mathrm{Cl} 1.13$ to 1.32) compared with those in the least deprived neighbourhoods, while the point estimate for inhaled steroids was higher, but fell just short of significance at the alpha $=0.05$ level $(\mathrm{RR}=1.16,95 \% \mathrm{Cl} 0.99$ to 1.34$)$. We did not observe community-level differences in problem list documentation of asthma or asthma severity.

Conclusions Higher neighbourhood-level social deprivation was associated with more albuterol and inhaled steroid prescriptions among children with asthma, while problem list documentation of asthma and asthma severity varied little across neighbourhoods with differing deprivation scores. While the homogeneity of the $\mathrm{CHC}$ safety net setting studied may mitigate variation in diagnosis and documentation of asthma, enhanced clinician awareness of differences in community risk could help target paediatric patients at risk of lower quality asthma care.

\section{INTRODUCTION}

Social determinants of health influence the quality of health outcomes and healthcare access for people with asthma. ${ }^{1-4}$ Increased asthma morbidity has been associated with

\section{Strengths and limitations of this study}

- This study uses electronic health record data from a multistate community health centre network linked with geocoded community-level data to examine the effect of neighbourhood social deprivation on asthma care quality.

- The Social Deprivation Index, a composite measure of 10 variables, was used to examine social deprivation among neighbourhoods.

- The data in this study were obtained from primary care clinics; therefore, we may have missed medication orders prescribed in the emergency department.

- We were not able to examine differences between specific Latino subgroups, as the data did not include subgroup information.

poor housing quality, ${ }^{15}$ single-parent households $^{6}$ and low socioeconomic status, ${ }^{3} 7$ all factors that contribute to social deprivation. ${ }^{8}$

The Social Deprivation Index (SDI) is a composite measure of neighbourhood-level social determinants of health, and can be used to measure disadvantages in healthcare access/outcomes across small geographical areas. ${ }^{9}$ The SDI has been used to identify where at-risk patients are located and explains more variability in health outcomes than poverty alone. ${ }^{910}$ Social deprivation has been linked to worse asthma outcomes and increased hospitalisation, ${ }^{71-14}$ yet these associations have not been studied at the patient level in the USA using geographically widespread longitudinal electronic health record (EHR) data linked in the context of community data. Community health centres (CHCs) receive federal funding to provide primary/ preventive care regardless of insurance status or ability to pay. ${ }^{15}$ They serve disproportionate numbers of patients in or near poverty and racial/ethnic minorities. ${ }^{16}$ This context is crucial in understanding the utility 
of indices such as the SDI in clinical settings serving the underserved. It helps illuminate at which point in the care of a chronic disease such as asthma social deprivation may play a role, and existing research with the SDI has not included this setting.

The objective of this study was to use patient-level data linked with geocoded community-level data over time to examine associations between neighbourhood social deprivation and asthma diagnosis documentation and care measures among children seeking care at CHCs. Previous associations between social deprivation and asthma exist, ${ }^{3} 711$ but do not directly correlate social deprivation with provision of asthma care. Because of the association with disease burden, we hypothesised that children living in areas with high levels of social deprivation would also have more asthma diagnoses documented on problem lists and more medications ordered than those living in less deprived areas.

\section{METHODS}

We used data from the Accelerating Data Value Across a National Community Health Center Network (ADVANCE) Clinical Research Network, a national network of CHCs. ${ }^{17}$ Our analysis includes EHR data from the OCHIN (not an acronym, formerly Oregon Community Health Information Network, until other states joined) network in 15 states. The majority of clinics were in California (33\%), Oregon (29\%), Ohio (13\%) and Massachusetts (12\%), with the rest in Alaska, Georgia, Indiana, Minnesota, Montana, North Carolina, Nevada, New Mexico, Texas, Washington and Wisconsin.

\section{Inclusion criteria}

Included in the study were children with asthma aged 3-17 who had $\geq 1$ ambulatory visit in study clinics between 2008 and 2017, and who had an address that, when geocoded, allowed identification of the census tract in which the patient resided. Non-Hispanic white, non-Hispanic black and Latino children were included in this analysis. We identified asthma in this population when $\geq 1$ International Classification of Diseases (ICD)-9 code of $493^{*}$ or ICD-10 codes of J45* were captured in any encounter between 2008 and 2017. The majority of children in our sample $(65.8 \%)$ had $\geq 2$ asthma diagnoses during the study period. While there is currently no standard in defining asthma cases epidemiologically, ICD codes have been found to be valuable in research using EHR data. ${ }^{18-20}$

\section{Outcomes}

The outcome variables were binary indicators of (1) asthma documented on the problem list ever, and (2) having asthma severity documented on the problem list ever. Our intent was not to measure asthma prevalence (ie, not merely which children were ever noted to have asthma anywhere in the record), but to measure the care for asthma as a chronic illness. Problem list documentation was our proxy for documenting asthma as a chronic condition, as research has shown that use of the problem list is associated with higher quality clinical care,,${ }^{22}$ and use of a problem list is a feature of commonly recommended care for chronic conditions, as well as being a quality measure for the use of EHR. ${ }^{22-25}$ Documenting asthma severity is necessary to determine appropriate medication prescription. ${ }^{26}$ Asthma and asthma severity were determined using ICD-9 or ICD-10 codes (online supplemental appendix table 1). Additional outcome measures included rates of (1) albuterol prescription, (2) inhaled steroid prescription, and (3) oral steroid prescription. Prescriptions for asthma medications were based on ordered medications, and medications were identified by National Drug Codes, reviewed and cleaned by analysts and reviewed again for final categorisation by a practising clinician (online supplemental appendix table 1).

\section{Independent variables}

The main independent variable was a categorical version of the SDI, a composite measure of deprivation from 10 variables in the following seven domains: income, education, employment, housing, household characteristics, transportation and demographics created by the Robert Graham Center (online supplemental appendix table 2). The SDI uses the 2011-2015 American Community Survey 5-year estimate. ${ }^{927}$ Quartiles of the SDI score (unitless range of 0-100) were calculated based on the distribution of the score in our patient sample and used in the analysis as has been done in other studies ${ }^{51028}$ with the lowest quartile (Q1, SDI scores ranging from 0 to 56 ) representing the least deprived neighbourhoods at the census tract level, and the highest quartile (Q4, SDI scores ranging from 93 to 100) representing the neighbourhoods with the most deprivation at the census tract level. Q3 included SDI scores from 80 to 92, and Q2 included SDI scores ranging from 57 to 79 . A patient's neighbourhood was determined at the census tract where, based on addresses recorded in the EHR, the patient resided for the longest cumulative duration during the study period. We also constructed a binary indicator that specified whether a patient ever reported an address change to a different census tract to serve as a covariate (referred to as 'neighborhood change').

Additional covariates included patient-level characteristics: age in years at first visit at a study clinic, ${ }^{3-17}$ sex (female or male), rate of visits per year $(<1,1-2,3-4, \geq 5)$, insurance during the study period recorded at each visit (never insured, private insurance used at $\geq 1$ visit, public insurance used at $\geq 1$ visit, a combination of public and private insurance) and race/ethnicity (Latino, nonHispanic white and non-Hispanic black). While we generally use Latino/Latina because it is often preferred in populations similar to our study population, the actual ethnicity information collected by clinics is 'Hispanic' and 'non-Hispanic'. We included body mass index (BMI), denoted as never overweight/obese, overweight/obese at $\geq 1$, but not all clinic visits, or overweight/obese at every 
clinic visit. Overweight/obese was defined as having a BMI $\geq 85$ th percentile for one's respective age and sex, consistent with Centers for Disease Control and Prevention standards. ${ }^{29}$ BMI and BMI percentile were calculated at the encounter level using the R package childsds. ${ }^{30} \mathrm{We}$ also included an indicator of family-level poverty (federal poverty level (FPL) ) measured at each visit over the course of the study period (always $\geq 138 \%$ FPL, always $<138 \%$ FPL, above and below 138\% FPL and not documented at visits (to account for missing data)). Smoking exposure was also assessed in three groups: (1) never exposed, (2) ever exposed (this includes patients or parents who are current or ever smokers, and children exposed to secondhand smoke), and (3) unknown if exposed.

\section{Statistical analysis}

Descriptive analyses were conducted to examine patient characteristics. For binary outcomes (ie, asthma and asthma severity documented in the problem list), we used generalised estimating equations logistic regression models as a function of SDI quartiles, adjusted for all covariates listed above. Models were fitted with a compound symmetry correlation structure and empirical sandwich variance estimator to obtain adjusted ORs and their corresponding 95\% CIs, accounting for clustering of patients within CHCs. For the analyses evaluating prescription rates, we used negative binomial regression (due to overdispersion) to estimate adjusted rate ratios (RRs) of prescription separately for albuterol, inhaled steroids and oral steroids, also while accounting for clustering of patients by CHC.

$\mathrm{R}$ and Stata software were used to perform statistical analysis. ${ }^{31}$ Two-sided statistical significance was set at $\mathrm{p}<0.05$. The data used in this study are collected during routine primary care and consent from patients to use data in research is obtained from clinics. The data are deidentified before transfer to the study team.

\section{Patient and public involvement}

Our network has a panel of patients who review all research and reviewed our larger project on asthma disparities; patients were not directly involved in the design and conduct of this specific analysis.

\section{RESULTS}

The sample included 34266 children across 15 states. Table 1 shows patient characteristics. The largest proportion of children were Latino $(47.2 \%)$, followed by non-Hispanic white $(27.8 \%)$, then non-Hispanic black $(25.0 \%)$. More than half of the population was male $(56.2 \%)$ and many patients first received care at a $\mathrm{CHC}$ at ages $3-5$ years $(44.6 \%)$ or ages $6-10$ years $(32.1 \%)$. Most patients had some public insurance $(83.0 \%)$ and one to two ambulatory visits per year $(43.2 \%)$. Overall, $33.6 \%$ of patients were overweight/obese at every visit and $37.4 \%$ were never overweight/obese. More than half of the population $(53.6 \%)$ did not have a change in neighbourhood.
Most children lived in a household that was $<138 \%$ FPL at every ambulatory visit (61.2\%). The majority of the sample did not have documented tobacco smoke exposure, direct or indirect $(70.3 \%)$. The majority of children living in neighbourhoods with the most community deprivation (top quartile, Q4) were Latino $(53.6 \%)$ or non-Hispanic black (36.9\%), had used public insurance at $\geq 1$ clinic visit $(90.7 \%)$ and more than one-third always had an overweight or obese BMI recorded at clinic visits $(35.0 \%)$. Among the children living in the quartile with the least deprivation (lowest quartile, Q1), most were nonHispanic white $(53.7 \%)$ or Latino (35.0\%), $71.6 \%$ used public insurance at $\geq 1$ clinic visit and $30.4 \%$ always had an overweight or obese BMI recorded at clinic visits. Similar numbers of children in Q1 (44.9\%) and Q4 (41.4\%) had neighbourhood changes (table 1 ).

Across the study period, $75.4 \%$ of patients had asthma documented on their problem list and $21.2 \%$ had asthma severity documented on the problem list. Albuterol prescription was 1.88 prescriptions per year, on average. Inhaled steroids were prescribed an average of 0.52 times per year, and there was an average of 0.35 oral steroid prescriptions each year. Online supplemental appendix table 3 shows these unadjusted outcomes by SDI quartile. Children living in the areas with the most deprivation more often had asthma documented on their problem lists $(80.1 \%)$ compared with children living in the areas with the least deprivation $(70.7 \%)$. The same trend was observed for asthma severity documentation $(25.8 \%$ vs $17.7 \%)$.

From table 2, the adjusted odds of having asthma recorded on the problem list were similar among children living in all quartiles. Non-Hispanic black children had $32 \%$ greater odds of having asthma on the problem list than non-Hispanic white children. As the number of visits increased, the odds of asthma on the problem list also increased (table 2).

Children with asthma had the same odds of having asthma severity documented on the problem list, regardless of where they lived. We observed increased odds of asthma severity documentation as number of visits increased (table 2). Children who moved to a different neighbourhood during the study period had lower odds of having asthma severity documented compared with those with no change in neighbourhood ( $\mathrm{OR}=0.90,95 \%$ CI 0.85 to 0.95 ).

Among children with asthma (figure 1, online supplemental appendix table 4 ), we observed a trend that as SDI increased, the rate of albuterol also increased by $8 \%, 15 \%$ and $22 \%(\mathrm{Q} 2: \mathrm{RR}=1.08,95 \%$ CI 1.02 to 1.14 ; $\mathrm{Q} 3: \mathrm{RR}=1.15$, 95\% CI 1.09 to 1.22 ; $\mathrm{Q} 4: \mathrm{RR}=1.22,95 \%$ CI 1.13 to 1.32 ).

For inhaled steroid prescriptions, all quartiles had similar rates of inhaled steroid prescriptions as in Q1; however, rates trended upwards with increased deprivation, and the rates of those in Q4, compared with those in $\mathrm{Q} 1$, neared significance ( $\mathrm{RR}=1.16,95 \%$ CI 0.99 to 1.34 ).

Lastly, the rates of oral steroid prescription were similar between children living in any neighbourhood compared 
Table 1 Patient characteristics overall and by Social Deprivation Index score quartile $(n=34266)$

\begin{tabular}{|c|c|c|c|c|c|}
\hline & $\begin{array}{l}\text { Overall } \\
\text { n (\%) }\end{array}$ & $\begin{array}{l}\text { Quartile } 1 \\
(0-56) \\
\text { n (\%) }\end{array}$ & $\begin{array}{l}\text { Quartile } 2 \\
\text { (57-79) } \\
\text { n (\%) }\end{array}$ & $\begin{array}{l}\text { Quartile } 3 \\
(80-92) \\
\text { n (\%) }\end{array}$ & $\begin{array}{l}\text { Quartile } 4 \\
(93-100) \\
\text { n (\%) }\end{array}$ \\
\hline \multicolumn{6}{|l|}{ Race/ethnicity } \\
\hline Latino & $16160(47.2)$ & $2523(35.0)$ & 3676 (45.2) & 4368 (51.4) & $5593(53.6)$ \\
\hline Non-Hispanic black & $8571(25.0)$ & $815(11.3)$ & $1434(17.6)$ & $2475(29.2)$ & $3847(36.9)$ \\
\hline Non-Hispanic white & $9535(27.8)$ & $3868(53.7)$ & 3019 (37.2) & $1648(19.4)$ & $1000(9.6)$ \\
\hline \multicolumn{6}{|l|}{ Age at first encountert (years) } \\
\hline $3-5$ & 15295 (44.6) & 3019 (41.9) & $3838(47.2)$ & 4010 (47.2) & $4428(42.4)$ \\
\hline $6-10$ & $11000(32.1)$ & 2374 (32.9) & $2578(31.7)$ & 2585 (30.4) & $3463(33.2)$ \\
\hline $11-13$ & 5007 (14.6) & 1179 (16.4) & 1096 (13.5) & $1178(13.9)$ & $1554(14.9)$ \\
\hline $14-17$ & $2964(8.7)$ & $634(8.8)$ & $617(7.6)$ & $718(8.5)$ & $995(9.5)$ \\
\hline \multicolumn{6}{|l|}{ Sex } \\
\hline Female & $15010(43.8)$ & 3203 (44.5) & $35 \underline{77}(44.0)$ & 3642 (42.9) & $4588(44.0)$ \\
\hline Male & $19256(56.2)$ & $4003(55.6)$ & $4552(56.0)$ & $4849(57.1)$ & $5852(56.1)$ \\
\hline \multicolumn{6}{|l|}{ Insurance type } \\
\hline Never insured & $830(2.4)$ & $245(3.4)$ & $224(2.8)$ & $188(2.2)$ & $173(1.7)$ \\
\hline Public insurance used at $>1$ clinic visit & $28451(83.0)$ & $5161(71.6)$ & $6514(80.1)$ & $7304(86.0)$ & $9472(90.7)$ \\
\hline Private insurance used at $>1$ clinic visit & $2473(7.2)$ & $1067(14.8)$ & $680(8.4)$ & $422(5.0)$ & $304(2.9)$ \\
\hline Public and private insurance & $2512(7.3)$ & $733(10.2)$ & $711(8.8)$ & $577(6.8)$ & $491(4.7)$ \\
\hline \multicolumn{6}{|l|}{ Visits per yearf } \\
\hline$<1$ & 4878 (14.2) & $1122(15.6)$ & $1232(15.2)$ & $1147(13.5)$ & $1377(13.2)$ \\
\hline $1-2$ & $14803(43.2)$ & $3320(46.1)$ & 3671 (45.2) & $3731(43.9)$ & $4081(39.1)$ \\
\hline $3-4$ & 7825 (22.8) & $1608(22.3)$ & $1802(22.2)$ & $2003(23.6)$ & $2412(23.1)$ \\
\hline$\geq 5$ & $6760(19.7)$ & $1156(16.0)$ & $1424(17.5)$ & $1610(19.0)$ & $2570(24.6)$ \\
\hline \multicolumn{6}{|l|}{ BMI category } \\
\hline Never overweight/obese & $12823(37.4)$ & 3009 (41.8) & $2988(36.8)$ & 2991 (35.2) & $3835(36.7)$ \\
\hline$>1$ visit with overweight/obese BMI & 9941 (29.0) & $2006(27.8)$ & 2506 (30.8) & 2478 (29.2) & $2951(28.3)$ \\
\hline Always overweight/obese & 11502 (33.6) & $2191(30.4)$ & 2635 (32.4) & $3022(35.6)$ & $3654(35.0)$ \\
\hline \multicolumn{6}{|l|}{ Neighbourhood change } \\
\hline Yes & $15918(46.5)$ & $3236(44.9)$ & $4141(50.9)$ & $4220(49.7)$ & $4321(41.4)$ \\
\hline No & $18348(53.6)$ & $3970(55.1)$ & $3988(49.1)$ & $4271(50.3)$ & $6119(58.6)$ \\
\hline \multicolumn{6}{|l|}{$\%$ federal poverty level } \\
\hline Always $\geq 138$ & $1967(5.7)$ & 709 (9.8) & $614(7.6)$ & $387(4.6)$ & $257(2.5)$ \\
\hline Above and below 138 & 4489 (13.1) & $1201(16.7)$ & $1384(17.0)$ & $1132(13.3)$ & $772(7.4)$ \\
\hline Always $<138$ & 20955 (61.2) & 3717 (51.6) & 4595 (56.5) & $5461(64.3)$ & $7182(68.8)$ \\
\hline Not documented & $6855(20.0)$ & $1579(21.9)$ & 1536 (18.9) & $1511(17.8)$ & $2229(21.4)$ \\
\hline \multicolumn{6}{|l|}{ Smoking exposure } \\
\hline Never exposed & $24094(70.3)$ & $5193(72.1)$ & $5912(72.7)$ & $6128(72.2)$ & $6861(65.7)$ \\
\hline Ever exposed & 4964 (14.5) & $988(13.7)$ & $1113(13.7)$ & $1084(12.8)$ & $1779(17.0)$ \\
\hline Unknown if exposed & 5208 (15.2) & 1025 (14.2) & 1104 (13.6) & $1279(15.1)$ & $1800(17.2)$ \\
\hline
\end{tabular}

${ }^{*}$ Quartile 1 of the Social Deprivation Index score represents neighbourhoods with the least deprivation and quartile 4 represents neighbourhoods with the most deprivation.

†Children aged 3-5 are often in preschool/kindergarten, while those aged 6-10 are in elementary school. Children aged 11-13 are in middle school and those aged 14-17 are of high school age. We anticipated possible differences in experience based on age, as asthma changes over childhood, and age is also a proxy for utilisation.

$\ddagger$ Visits per year include all ambulatory visits.

BMI, body mass index. 
Table 2 Adjusted ORs of asthma and asthma severity documentation on the problem list $(n=34266)$

\section{Adjusted OR of asthma documented Adjusted OR of asthma severity on problem list documented on problem list OR $(95 \% \mathrm{Cl})$ OR $(95 \% \mathrm{Cl})$}

Social Deprivation Index score*

$\begin{array}{lll}\text { Quartile 1 } & \text { Ref } & \text { Ref } \\ \text { Quartile 2 } & 1.01(0.94 \text { to } 1.08) & 1.04(0.96 \text { to } 1.13) \\ \text { Quartile 3 } & 1.02(0.95 \text { to } 1.09) & 1.01(0.92 \text { to } 1.09) \\ \text { Quartile 4 } & 1.00(0.92 \text { to } 1.08) & 1.02(0.93 \text { to } 1.12)\end{array}$

Race/ethnicity

\begin{tabular}{|c|c|c|}
\hline Non-Hispanic white & Ref & Ref \\
\hline Latino & 1.05 (0.97 to 1.12$)$ & 1.00 (0.90 to 1.10$)$ \\
\hline Non-Hispanic black & $1.32(1.20$ to 1.46$)$ & 1.08 (0.97 to 1.21$)$ \\
\hline \multicolumn{3}{|l|}{ Age at first encounter (years) } \\
\hline $3-5$ & Ref & Ref \\
\hline $6-10$ & $1.32(1.23$ to 1.42$)$ & 1.15 (1.05 to 1.25$)$ \\
\hline $11-13$ & 1.19 (1.09 to 1.30$)$ & 1.14 (1.01 to 1.29$)$ \\
\hline $14-17$ & $0.99(0.90$ to 1.09$)$ & 1.44 (1.19 to 1.75$)$ \\
\hline \multicolumn{3}{|l|}{ Sex } \\
\hline Female & Ref & Ref \\
\hline Male & $1.16(1.08$ to 1.21$)$ & 0.97 (0.92 to 1.02$)$ \\
\hline \multicolumn{3}{|l|}{ Insurance type } \\
\hline Private insurance used at $>1$ clinic visit & Ref & Ref \\
\hline Never insured & 0.86 (0.73 to 1.01$)$ & 1.62 (1.33 to 1.97$)$ \\
\hline Public insurance used at $>1$ clinic visit & 1.05 (0.96 to 1.15$)$ & 1.08 (0.96 to 1.22$)$ \\
\hline Public and private insurance & 1.12 (0.99 to 1.27$)$ & 0.88 (0.77 to 1.00$)$ \\
\hline \multicolumn{3}{|l|}{ Visits per yeart } \\
\hline$<1$ & Ref & Ref \\
\hline $1-2$ & $1.18(1.10$ to 1.26$)$ & 2.04 (1.80 to 2.30$)$ \\
\hline $3-4$ & 1.41 (1.28 to 1.55$)$ & 2.94 (2.57 to 3.37 ) \\
\hline$\geq 5$ & 1.50 (1.34 to 1.67$)$ & 417 (3.60 to 4.83$)$ \\
\hline \multicolumn{3}{|l|}{ BMI category } \\
\hline Never overweight/obese & Ref & Ref \\
\hline$\geq 1$ visit with overweight/obese BMI & 1.19 (1.12 to 1.26$)$ & 0.91 (0.84 to 0.98$)$ \\
\hline Always overweight/obese & $1.14(1.08$ to 1.20$)$ & 0.96 (0.90 to 1.02$)$ \\
\hline \multicolumn{3}{|l|}{$\%$ federal poverty level } \\
\hline Always $\geq 138$ & Ref & Ref \\
\hline Above and below 138 & 1.13 (0.99 to 1.28$)$ & 0.81 (0.70 to 0.93 ) \\
\hline Always $<138$ & $1.10(0.99$ to 1.21$)$ & 0.92 (0.82 to 1.03$)$ \\
\hline Not documented & $1.00(0.88$ to 1.13$)$ & 0.93 (0.80 to 1.08$)$ \\
\hline \multicolumn{3}{|l|}{ Neighbourhood change } \\
\hline No & Ref & Ref \\
\hline Yes & 1.04 (1.00 to 1.09 ) & 0.90 (0.85 to 0.95$)$ \\
\hline \multicolumn{3}{|l|}{ Smoking exposure } \\
\hline Never exposed & Ref & Ref \\
\hline Ever exposed & 1.13 (1.05 to 1.21$)$ & 0.98 (0.90 to 1.08 ) \\
\hline Unknown if exposed & 1.01 (0.93 to 1.10$)$ & 0.90 (0.80 to 1.02$)$ \\
\hline
\end{tabular}




\section{Adjusted OR of asthma documented on problem list OR $(95 \% \mathrm{Cl})$ \\ Adjusted OR of asthma severity documented on problem list OR $(95 \% \mathrm{Cl})$}

${ }^{*}$ Quartile 1 of the Social Deprivation Index (SDI) score represents neighbourhoods with the least deprivation and quartile 4 represents neighbourhoods with the most deprivation. The SDI is a composite measure of deprivation from 10 variables in the following seven domains: income, education, employment, housing, household characteristics, transportation and demographics created by the Robert Graham Center using 2011-2015 American Community Survey 5-year estimates. †Visits per year include all ambulatory visits. $\mathrm{BMI}$, body mass index.

with those living in neighbourhoods in Q1. For all medications, non-Hispanic black children had higher rates of prescriptions than did non-Hispanic white children. The rates of albuterol and oral steroid prescriptions were also greater for Latino children compared with non-Hispanic white children (online supplemental appendix table 4).

\section{DISCUSSION}

This study is the first of which we are aware that links geocoded patient-level EHR data and an ecological measure of social deprivation to determine the relationship between area deprivation and documented asthma care and prescribing in a national primary care cohort. We found similar odds of asthma or asthma severity documented on the problem list between the four SDI quartiles when adjusted for relevant covariates. This suggests that this step in chronic asthma care appears to be equal for children receiving care in CHCs, regardless of the socioeconomic status of the neighbourhoods in which they reside. Moreover, among these children with diagnosed asthma, Latino and non-Hispanic black children also had higher odds of documentation of asthma on their problem lists than did non-Hispanic white children, suggesting that children with increased risks associated with asthma are receiving quality care from CHCs. These

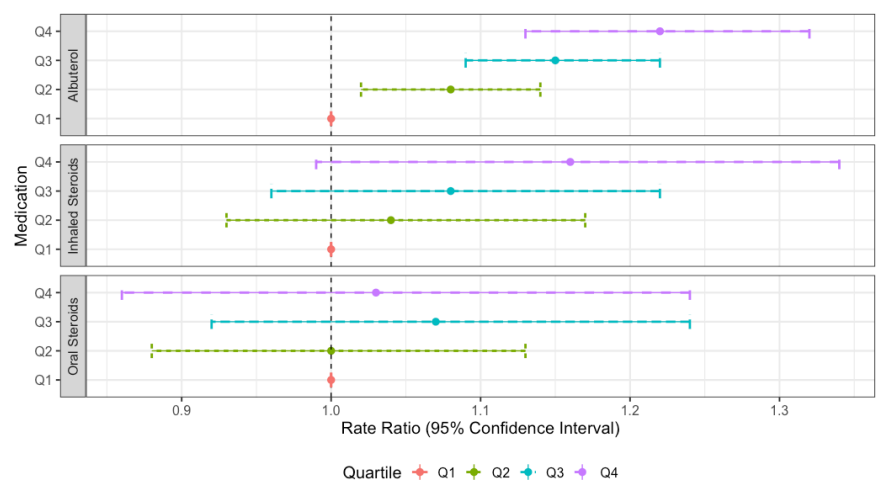

Figure 1 Rate ratios of asthma medication prescriptions $(n=34$ 266). All models adjusted for race/ethnicity, age, sex, insurance type, visits/year, body mass index (BMI), neighbourhood change, \% federal poverty level (FPL) and smoking exposure. Quartile 1 (Q1) of the Social Deprivation Index (SDI) score represents neighbourhoods with the least deprivation and quartile 4 (Q4) represents neighbourhoods with the most deprivation. Reference group is Q1. findings are consistent with previous research, which has shown that CHCs may be a factor in mitigating racial/ ethnic disparities, as well as in lessening disparities related to the access and utilisation of care. ${ }^{32-34}$

The adjusted rate of albuterol prescription increased as neighbourhood deprivation increased, indicating that more emergency medication was prescribed in neighbourhoods with greater deprivation. Albuterol prescription may be an indicator of asthma symptoms, and asthma symptoms might increase as community deprivation increases. ${ }^{1214}$

The adjusted rate of inhaled steroids trended higher and approached significance in the most deprived quartile compared with the least deprived quartile, again possibly indicating that asthma symptoms are worse in communities with more deprivation. The adjusted rate of oral steroid prescription did not differ between quartiles. This could be because oral steroids are often prescribed for exacerbations in emergency situations instead of at primary care visits, and may not have been captured as much as albuterol or inhaled steroid, both frequently prescribed in the primary care setting.

Understanding that social deprivation was associated with greater medication prescription, with other important factors held constant, may be of practical value to the healthcare providers and policymakers. Clinics and other health authorities can use social deprivation data to plan for elevated medication (or other care) needs in more deprived areas. In delivering care to underserved patients who use CHCs, neighbourhood social deprivation level may be a better indicator of care need over the patient's documented asthma severity. This may involve in-clinic social determinants of health screening, neighbourhood assessments or other tools to more proactively estimate asthma needs and to provide close follow-up on medication effectiveness, adherence and other aspects of disease management.

Children who were never insured were more likely than those who were privately insured to have asthma severity documented on the problem list. This is a surprising finding, but demonstrates that CHCs deliver quality chronic disease care to those with the least resources. Classifying asthma severity is one of the first steps in long-term asthma management to improve control and prevent exacerbations that can lead to increased hospitalisation or use of emergency/urgent care. ${ }^{26}$ Our 
findings underscore that while children living in more deprived areas may require more asthma medications, they do receive the required care (or at least have it ordered) in CHCs, reinforcing the vital link that these health centres play in deprived communities. Our study provides evidence that these centres and the populations they serve require important resources, and that CHCserved populations are targets for asthma intervention. Finally, children who moved residence also had lower odds of documentation of asthma and asthma severity on their problem lists than children who stayed in the same area. This may be a concrete demonstration of the healthcare disruption that may be associated with residential mobility or transience. This needs further research, but providers and clinics can be attuned to children with changing addresses, and consider devoting resources towards outreach to those children to ensure there is no interruption in care.

This study had several limitations. Our data came from primary care clinics, so it is possible that we did not account for oral steroids prescribed in emergency departments. Additionally, primary care clinics in the USA often do not do comprehensive allergy testing so our data do not contain history of atopy and $\operatorname{IgE}$ laboratory results in a consistent manner. Children with severe asthma and allergies are commonly referred to allergy and immunology specialists. Furthermore, we did not have access to pharmacy data, so we did not know if prescriptions were filled, only that they were ordered. Further research using pharmacy data for asthma medications in this population may be needed. We also were not able to study differences between specific Latino subgroups, as our data did not include subgroup information. We were not able to include Asian children, as the sample was too small $(\sim 3 \%)$ for meaningful analysis. Future research can examine these phenomena in both of those sets of patients. We were not able to determine if asthma was the primary diagnosis at each visit, but, given our long study period, could measure whether these care measures ever occurred, which is consistent with clinical practice guidelines. Lastly, we were not able to include urban versus rural environment in our models because more than $98 \%$ of our population visited clinics in urban environments.

\section{CONCLUSION}

Social determinants of health influence the care of patients with asthma seen in primary care settings, yet there is not a standardised way to understand these data in the context of a clinical care setting. We have used community data linked with clinical data via patient address to determine that social deprivation is associated with increased medication prescription despite similar documentation of asthma and asthma severity among these clinics; these findings reinforce the role CHCs play in communities with barriers to health and indirectly demonstrate the burden of disease in these communities. Proactive, risk-based asthma care across communities could be obtained if health systems were provided with regular access to administrative deprivation data such as the SDI to then inform locally targeted policies and interventions to improve asthma management and education at a community level.

\section{Twitter Miguel Marino @MmMiguelmM}

Acknowledgements This research was conducted with Accelerating Data Value Across a National Community Health Center Network (ADVANCE) Clinical Research Network (CRN), a member of PCORnet, an initiative originally funded by the PatientCentered Outcomes Research Institute (PCORI) and now funded by the PeopleCentered Research Foundation (PCRF). The ADVANCE network is led by OCHIN in partnership with Health Choice Network, Fenway Health, Oregon Health \& Science University and the Robert Graham Center/HealthLandscape. ADVANCE is funded through PCRF (contract number 1237).

Contributors JAL and MM conceptualised and designed the study, drafted the initial manuscript, supervised data collection, analysed the data, and reviewed and revised the manuscript. JH conceptualised and designed the study, and reviewed and revised the manuscript. KF created the analytical data set, contributed to the analytical design, helped interpret findings, and reviewed and revised the manuscript. AB helped interpret findings, and reviewed and revised the manuscript. SG, SC, JK and DEH collected and cleaned the data, contributed to the analytical design, helped interpret findings, and reviewed and revised the manuscript. All authors approved the final manuscript as submitted and agree to be accountable for all aspects of the work.

Funding This work was supported by an NIH National Institute on Minority Health and Health Disparities grant (R01MD011404; BACKGROUND Study, principal investigator: JH).

Competing interests None declared.

Patient consent for publication Not required.

Ethics approval This study has been approved by the Oregon Health \& Science University Institutional Review Board (STUDY00017724).

Provenance and peer review Not commissioned; externally peer reviewed.

Data availability statement Data may be obtained from a third party and are not publicly available. Data are a limited (partially deidentified) data set from electronic health records. Data are available to investigators for a fee and willing and able to partner with OCHIN on their analysis.

Supplemental material This content has been supplied by the author(s). It has not been vetted by BMJ Publishing Group Limited (BMJ) and may not have been peer-reviewed. Any opinions or recommendations discussed are solely those of the author(s) and are not endorsed by BMJ. BMJ disclaims all liability and responsibility arising from any reliance placed on the content. Where the content includes any translated material, BMJ does not warrant the accuracy and reliability of the translations (including but not limited to local regulations, clinical guidelines, terminology, drug names and drug dosages), and is not responsible for any error and/or omissions arising from translation and adaptation or otherwise.

Open access This is an open access article distributed in accordance with the Creative Commons Attribution Non Commercial (CC BY-NC 4.0) license, which permits others to distribute, remix, adapt, build upon this work non-commercially, and license their derivative works on different terms, provided the original work is properly cited, appropriate credit is given, any changes made indicated, and the use is non-commercial. See: http://creativecommons.org/licenses/by-nc/4.0/.

ORCID iD

Jennifer A Lucas http://orcid.org/0000-0002-2895-9809

\section{REFERENCES}

1 Hughes HK, Matsui EC, Tschudy MM, et al. Pediatric asthma health disparities: race, hardship, housing, and asthma in a national survey. Acad Pediatr 2017;17:127-34.

2 Williams DR, Sternthal M, Wright RJ. Social determinants: taking the social context of asthma seriously. Pediatrics 2009;123 Supp 3:S174-84.

3 Beck AF, Huang B, Simmons JM, et al. Role of financial and social hardships in asthma racial disparities. Pediatrics 2014;133:431-9. 
4 World Health Organization. Social determinants of health, 2019. Available: https://www.who.int/social_determinants/en/

5 Beck AF, Huang B, Chundur R, et al. Housing code violation density associated with emergency department and hospital use by children with asthma. Health Aff 2014;33:1993-2002.

6 Moncrief T, Beck AF, Simmons JM, et al. Single parent households and increased child asthma morbidity. Journal of Asthma 2014;51:260-6.

7 Brewer M, Kimbro RT, Denney JT, et al. Does neighborhood social and environmental context impact race/ethnic disparities in childhood asthma? Health Place 2017;44:86-93.

8 Phillips RL, Liaw W, Crampton P, et al. How other countries use deprivation Indices-And why the United States desperately needs one. Health Aff 2016;35:1991-8.

9 Butler DC, Petterson S, Phillips RL, et al. Measures of social deprivation that predict health care access and need within a rational area of primary care service delivery. Health Serv Res 2013;48:539-59.

10 Liaw W, Krist AH, Tong ST, et al. Living in "Cold Spot" Communities Is Associated with Poor Health and Health Quality. J Am Board Fam Med 2018;31:342-50.

11 Nkoy FL, Stone BL, Knighton AJ, et al. Neighborhood deprivation and childhood asthma outcomes, accounting for insurance coverage. Hosp Pediatr 2018:59-67.

12 Roberts SE, Button LA, Hopkin JM, et al. Influence of social deprivation and air pollutants on serious asthma. Eur Respir $J$ 2012;40:785-8.

13 Burr ML, Verrall C, Kaur B. Social deprivation and asthma. Respir Med 1997:91:603-8.

14 Gupta RP, Mukherjee M, Sheikh A, et al. Persistent variations in national asthma mortality, hospital admissions and prevalence by socioeconomic status and region in England. Thorax 2018;73:706-12.

15 Administration HRS. Health center program: what is a health center? 2018. Available: https://bphc.hrsa.gov/about/what-is-a-healthcenter/index.html

16 National Association of Community Health Centers. Community health center Chartbook, 2018.

17 DeVoe JE, Gold R, Cottrell E, et al. The advance network: accelerating data value across a national community health center network. J Am Med Inform Assoc 2014;21:591-5.

18 Luhn P, Kuk D, Carrigan G, et al. Validation of diagnosis codes to identify side of colon in an electronic health record registry. BMC Med Res Methodol 2019;19:177.

19 Tang PC, Ralston M, Arrigotti MF, et al. Comparison of methodologies for calculating quality measures based on administrative data versus clinical data from an electronic health record system: implications for performance measures. J Am Med Inform Assoc 2007;14:10-15.
20 Nissen F, Quint JK, Wilkinson S, et al. Validation of asthma recording in electronic health records: a systematic review. Clin Epidemiol 2017;9:643-56

21 Poon EG, Wright A, Simon SR, et al. Relationship between use of electronic health record features and health care quality: results of a statewide survey. Med Care 2010;48:203-9.

22 Jolly SE, Navaneethan SD, Schold JD, et al. Chronic kidney disease in an electronic health record problem list: quality of care, ESRD, and mortality. Am J Nephrol 2014;39:288-96.

23 Centers for Medicare and Medicaid Services. Eligible professional meaningful use core measures measure 3 of 13, 2014. Available: https://wwwcmsgov/Regulations-and-Guidance/Legislation/ EHRIncentivePrograms/downloads/3_Maintain_Problem_ListEPpdf

24 National Institute of Diabetes and Digestive and Kidney Diseases. Chronic care model. Available: https://wwwniddknihgov/healthinformation/communication-programs/ndep/health-professionals/ practice-transformation-physicians-health-care-teams/team-basedcare/chronic-care-model

25 Wright A, McCoy AB, Hickman T-TT, et al. Problem list completeness in electronic health records: a multi-site study and assessment of success factors. Int J Med Inform 2015;84:784-90.

26 National Heart L, and Blood Institute. Expert panel report 3 (EPR3) guidelines for the diagnosis and management of asthma, 2007. Available: http://www nhlbi nih gov/guidelines/asthma/

27 Center RG. Social Deprivation Index (SDI), 2018. Available: https:// wwwgraham-centerorg/rgc/maps-data-tools/sdi/social-deprivationindex.html

28 O'Lenick CR, Winquist A, Mulholland JA, et al. Assessment of neighbourhood-level socioeconomic status as a modifier of air pollution-asthma associations among children in Atlanta. J Epidemiol Community Health 2017;71:129-36.

29 Prevention CfDCa. Defining childhood obesity, 2018. Available: https://wwwcdcgov/obesity/childhood/defininghtml

30 Vogel M. childsds: data and methods around reference values in pediatrics. R package version 0.6.7, 2017. Available: https://CRANRprojectorg $/$ package $=$ childsds

31 Højsgaard S, Halekoh U, Yan J. The R package geepack for generalized estimating equations. Journal of Statistical Software $2005 ; 15: 11$

32 Zur J, Jones E. Racial and ethnic disparities among pediatric patients at community health centers. $J$ Pediatr 2015;167:845-50.

33 Heintzman JD, Bailey SR, Muench J, et al. Lack of lipid screening disparities in obese Latino adults at health centers. Am J Prev Med 2017;52:805-9.

34 Heintzman J, Bailey SR, Cowburn S, et al. Pneumococcal vaccination in low-income Latinos: an unexpected trend in Oregon community health centers. J Health Care Poor Underserved 2016;27:1733-44. 